\title{
Are the Slimmer More Wasteful? The Correlation between Body Mass Index and Food Wastage among Chinese Youth
}

\author{
Long Qian ${ }^{1}$, Feng $\mathrm{Li}^{2}$, Hongbo Liu ${ }^{3}$ and Lingen Wang ${ }^{4, *}$ \\ 1 Institute of Food and Strategic Reserves, Nanjing University of Finance and Economics, \\ Nanjing 210023, China; qianlongy101@126.com \\ 2 School of Economics, Nanjing University of Finance and Economics, Nanjing 210023, China; \\ leefeng_gifu@163.com \\ 3 Innovation and Development Institute, Anhui University, Hefei 230039, China; 19009@ahu.edu.cn \\ 4 Institute of Geographical Resources, Chinese Academy of Sciences, Beijing 100101, China \\ * Correspondence: wangle@igsnrr.ac.cn
}

check for updates

Citation: Qian, L.; Li, F.; Liu, H.; Wang, L. Are the Slimmer More Wasteful? The Correlation between Body Mass Index and Food Wastage among Chinese Youth. Sustainability 2022, 14, 1411. https://doi.org/ $10.3390 /$ su14031411

Academic Editor: Eleni Iacovidou

Received: 27 December 2021

Accepted: 20 January 2022

Published: 26 January 2022

Publisher's Note: MDPI stays neutral with regard to jurisdictional claims in published maps and institutional affiliations.

Copyright: (c) 2022 by the authors. Licensee MDPI, Basel, Switzerland. This article is an open access article distributed under the terms and conditions of the Creative Commons Attribution (CC BY) license (https:// creativecommons.org/licenses/by/ $4.0 /)$.

\begin{abstract}
With the economic growth and living standard improvement, food waste has become increasingly common among Chinese youth. To test whether body size affects the food waste performance of youth, we examined university students as representative of the Chinese youth and conducted a large-sample survey in 29 universities across 29 provinces. Based on 9192 questionnaires collected from Chinese college canteens, we found that body size was correlated with food waste. The smaller the body mass index (BMI) value, the higher the likelihood of plate waste, the higher the amount of waste, and the higher the ratio of food waste. Heterogeneity analyses revealed that BMI exerted a more significant impact on males than females, as well as a more substantial impact on northerners than southerners. Robust tests using other proxies to measure body size, robust regressions based on the new adjusted samples, and robust tests with an instrumental variable to overcome the endogenous issue suggested that the slimmer participants tended to be more wasteful. Hence, this study confirms that the slimmer youth tend to leave plate waste and waste more food per capita per meal. This study is the first attempt to analyze food wastage from the perspective of $\mathrm{BMI}$ in China to our best knowledge, and it provides a unique viewpoint for understanding young people's food wastage.
\end{abstract}

Keywords: food waste; BMI; body size; Chinese youth; university students

\section{Introduction}

Food wastage is a global phenomenon [1], and an estimated one-third of edible food is wasted worldwide [2]. Despite a low index given by the recent Food Waste Index Report 2021 of the United Nations Environment Programme (UNEP), it was also suggested that $17 \%$ of the total global food production is wasted at the consumer level [3]. Scholars concur that food wastage at the consumer stage is a severe issue in developed countries; hence, the majority of existing food consumption waste studies focus primarily on Western countries and communities. However, with an increase in income and the enhancement of living standards, food wastage has become more common in the developing world as well [4], although the related research in emerging countries is still rare, especially for China.

The mainstream literature specifies that food wastage by youth is more severe than that by elders $[5,6]$. Consequently, scholars have increasingly shown interest in food waste by youth $[7,8]$, especially young university/college students, which has garnered considerable attention lately. For example, Whitehair et al. [9] surveyed 540 students from Kansas State University, United States; Painter et al. [10] examined the leftovers of 205 students at Rhodes University, South Africa; Pinto et al. [11] conducted a follow-up investigation at Lisbon University, Portugal; and Burlea-Schiopoiu et al. [12] surveyed 375 students from Romanian universities. Likewise, similar studies have been conducted in Canada [13], 
Italy [14], South Korea [15], and other developed countries, but few in emerging countries such as China [16,17]. Hence, this study aims to investigate the food wastage of Chinese youth to enrich studies in this field.

Consistent with the existing literature, this study uses university students to represent young people. Per the latest data from the Ministry of Education of China (MEC), there are currently 2956 universities/colleges in mainland China, and the number of university students nationwide reached 37.535 million in 2019 [16]. Given the massive scale, it is imperative to elucidate the influential factors affecting the cohort's food consumption behavior before discussing food waste reduction policies. Unfortunately, little is known about the Chinese youth's food-wasting behavior.

Previous studies have attempted to clarify food wastage from the standpoint of traditional influencing factors [18,19], such as demographics, economic traits, social characteristics, social norms, and individual subjective perceptions (i.e., beliefs, attitudes, and tendencies). Nevertheless, almost no study has investigated the abovementioned issue from a body size or body mass index (BMI) perspective. BMI is one of the leading indicators for measuring body size internationally $[20,21]$. The related research shows that BMI is not only a simple medical indicator that affects an individual's health or psychology [22] but also significantly affects an individual's economic and social behavior, such as job acquisition and wages [23] and social interaction. As diet itself is the most common and most crucial socioeconomic behavior in people's daily lives, BMI might also closely correlate with an individual's food wastage. However, the impact of body size or BMI on food wastage has not been explored adequately [24]. However, this does not imply that the correlation between BMI and food waste has been overlooked by previous studies. Conversely, many studies have focused on how food intake affects an individual's BMI [25], and abundant studies have established that eating more (wasting less) is the most significant reason for obesity, because of excessive nutrient intake [26,27]. However, research on how BMI affects an individual's eating behavior, especially food waste, is scarce. Additionally, previous studies have not answered the question of whether or not the slim youth waste more food.

Hence, this study aims to investigate the food wastage generation of the Chinese youth and interpret their waste performance from the viewpoint of body size. Most of the existing studies are either based on case studies, small sample surveys, or using secondhand data [28]. Unlike previous studies, this study adopts the direct weighing method, a relatively accurate method, to acquire first-hand data of Chinese youth and conduct a largescale sample survey in 29 universities across 29 provinces. To the best of our knowledge, this is the first nationally representative survey on food wastage in Chinese universities.

The remainder of this paper is set up as follows: Section 2 is the literature review, which mainly summarizes the research related to food wastage; Section 3 presents the methodology, including data sources and collection, the variables set, and the empirical methods; Section 4 presents the results, including a descriptive analysis, a basic model based on the complete samples, heterogeneity analysis based on gender and different diet cultures, and robustness tests; Section 5 provides a discussion; and Section 6 includes conclusions.

\section{Literature Review}

In recent years, a growing number of scholars have focused on the topic of food waste [1]. Generally, the present research on food wastage can be divided into the following three categories.

Some studies have attempted to measure the scale of waste. A consensus reached by academics is that food wastage at the consumer stage is severer in developed countries; thus, the existing studies are primarily focused on the West $[12,19]$. However, related research in emerging countries has increased in recent years [29], revealing that food wastage has become more common in the developing world as well [2].

Some studies have focused on the economic and environmental effects of food wastage. A majority of these studies suggested that food wastage causes substantial economic losses and thus should be decreased [30,31]. The adverse environmental effects of food wastage 
are two-fold. Firstly, food wastage itself is a huge waste of resources because it requires large amounts of water, land, and other resources to produce food [32]. Secondly, food wastage also creates heavy metal pollution, water pollution, and greenhouse gas emissions during the decay process $[2,33]$. Some studies established that the adverse environmental effects of food wastage are severe and should be highly valued in many countries or regions [1].

Besides the two main research areas mentioned above, some studies have claimed that it is imperative to determine why people waste food $[10,34]$ in order to decrease food wastage. Understanding people's motivations to waste food helps identify what factors affect food wastage and supports proposing targeted measures to decrease food wastage [35]. The existing literature suggests that human decision-making is highly complicated. The subjective and objective characteristics, including demographic and economic factors [18], diet culture [6,36], social rules [37], perceptions [19], attitudes [38,39], dining factors [40], information intervention $[9,11]$, and other factors can affect food-wasting behavior. However, it was found that the impact of the above-listed factors is not consistent under different circumstances.

Although studies on food wastage are now abundant, previous studies are primarily about developed countries [5]. Similar studies in emerging countries, such as China, are relatively scarce [40]. China now ranks second worldwide in terms of GDP, and food wastage is becoming a growing concern in China with its rapid economic progress [4]. Thus, it is very urgent to conduct related studies in China. Besides, the existing studies suggest that food wastage occurs in multiple places [2], namely, households, restaurants, and public canteens, including elementary and middle school canteens and university cafeterias. Our literature review revealed several discussions of food wastage in Chinese households [41,42], elementary and middle schools [43,44], and restaurants [39,40]. Thus, it is urgent to add related studies in Chinese universities to completely understand the food wastage of Chinese consumers.

The university is a unique community comprising youth with a high level of education, which is a cohort thought to have a moral responsibility to decrease waste and move toward sustainable development [8]. Thus, the existing studies have primarily focused on food wastage by youth, especially the wastage by young university students [12,45], which has garnered considerable attention lately from scholars such as Wilkie and Graunke [46] in the United States, Painter et al. [10] in South Africa, and Rajan et al. [13] in Canada. However, most of these studies were conducted in developed countries, and similar research for Chinese youth is relatively rare [17].

Previous studies usually attempted to explain the food wastage of youth from the perspective of traditional influencing factors such as demographics, economic traits, and social characteristics. For example, a study on a sample of 328 students from Turkey suggested that moral attitude significantly affects the food wastage of youth [47]. Reportedly, the awareness of the environmental consequences of wasted food was significantly correlated with food waste for youth in the United States [7] and Italy [48]. In addition, knowledge and awareness about food waste were found to be correlated with the self-reported waste behavior of Malaysian youth [49]. Furthermore, Byker et al. [50] suggested that nutritional education is very helpful for decreasing food waste for youth in schools. However, no study interpreted food wastage from the perspective of body size or BMI [24].

Several studies have revealed that an individual's BMI exerts a non-negligible impact on food waste [49], but body size has only been considered as a crucial control variable in previous studies [51]. However, previous studies showed that BMI exerts a key influence on individual behavior and decision-making. The related research suggested that BMI affects an individual's health [52], job acquisition [23], and social interactions [53]. However, the impact of body size on individual food waste behavior has not been explored adequately. We believe that our study is among the first attempts to investigate food wastage from this unique perspective. 
Following on from previous studies [7], this study considered university students as representatives of the Chinese youth to investigate the impact of body size or BMI on an individual's food wastage. The contributions of this study are as follows: (i) it enriches the related studies on food wastage among Chinese youngsters, especially the wastage by young university students; (ii) it uses a nationwide survey to decrease the bias caused by case studies, small sample surveys [8,17], or second-hand data [27]; and (iii) it examines food waste from the unique perspective of body size. As BMI and food waste could be causal to each other $[25,45]$, a unique instrumental variable is introduced to manage the endogenous concern. Seemingly, this study is among the first attempts to introduce an instrumental variable to exclude the endogenous problem mentioned above. Furthermore, this study reliably confirms that slimmer youth tend to waste more food and produce more wastage. A better understanding of the food-wasting motivations of the youth would be helpful when forming policies to effectively reduce "waste on the tongue".

\section{Materials and Methods}

\subsection{Data Sources and Collection}

We conducted a nationwide survey at Chinese universities in 2018. One university from each province of mainland China, except for Tibet, was randomly chosen and surveyed. Unfortunately, owing to difficulties encountered in Henan Province, we dropped the data from Henan. Thus, 29 universities in 29 provinces were studied, covering most of mainland China, which is in line with of Qian et al. [16] (Figure 1).

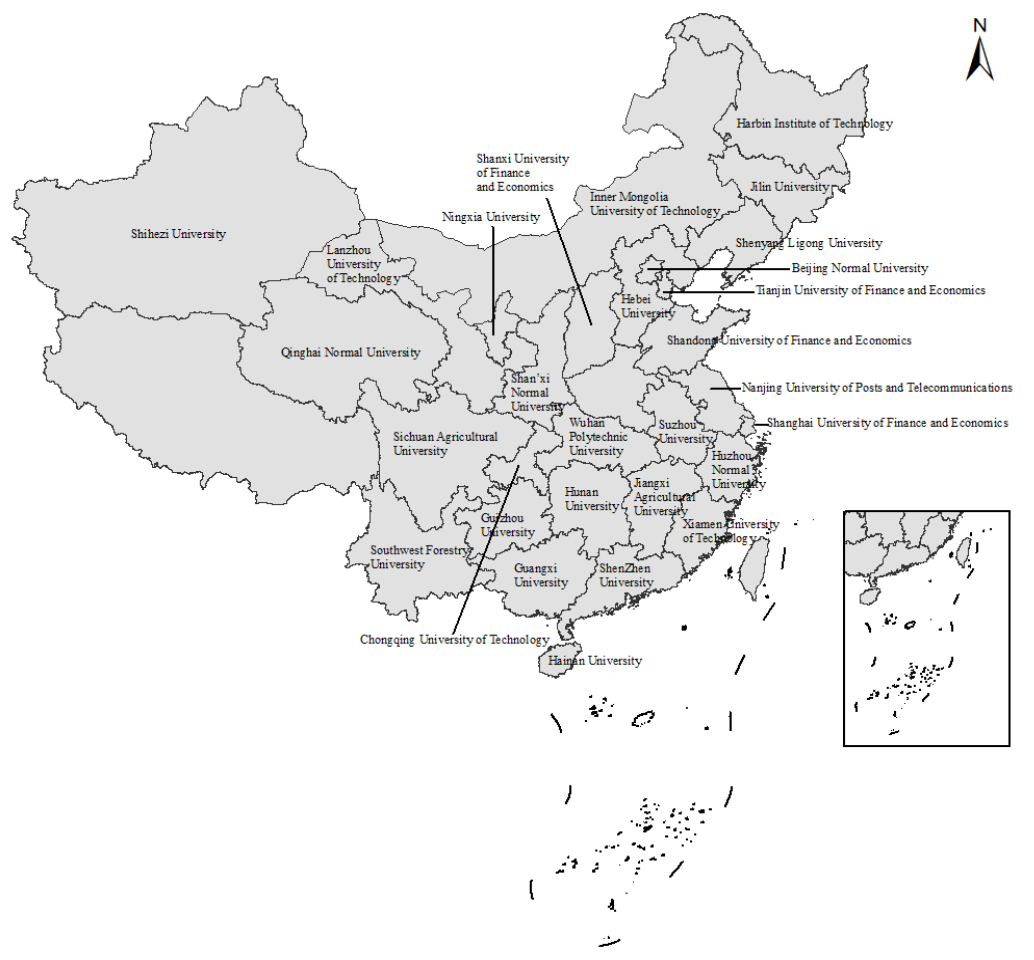

Figure 1. The surveyed universities in mainland China.

Two issues had to be addressed to obtain accurate food waste data. The first was to define food waste. The definition is not consistent in the existing literature. Following FAO's definition, we defined food waste as edible food discarded in the consumption process, which can be avoided under existing conditions [54]. Regarding specific operations, some parts unsuitable for consumption, such as vegetable skin, bean dregs, and bones, were not included in the category of food waste $[39,44]$. Furthermore, to compare the results with the existing studies on Western youth, the definition of food wastage in this survey was limited to solid residues [9]. Thus, the liquids, such as soups, cooking oil, 
and drinks, were excluded. The second issue was to determine how to obtain food waste data. To date, food diaries and second-hand data methods [27], visual estimation [33], self-report [34], the photography method [18], and the direct weighing methods have been used $[17,39]$. The direct weighing method is more objective, accurate, and reliable than the others $[16,45]$. Thus, the direct weighing method was adopted in this study, although it is more time-consuming and labor-intensive.

The questionnaire comprised two parts. The first part focused on the sociodemographic characteristics of the youth and the underlying factors affecting food wastage, including individual-level and family-level features, dining environment, information intervention, and regional characteristics. The second part was designed to record food wastage and the corresponding composition of leftovers. The survey was conducted at each university from Monday to Sunday to obtain the potential daily variances of waste [50]. Consistent with previous studies, the investigation involved lunch and supper only [55].

Since university students mainly eat in public cafeterias, university canteens were selected as the investigation places. In China, university students mainly eat in university dining facilities. Following previous studies [56], trained surveyors purchased the foods served in the canteens during lunch or dinner and weighed them with electronic scales to obtain the standard weight before meals. When a student finished his/her meal, the investigator first sought survey permission. Once the permission was granted, the respondent's personal information was requested and recorded. The respondent was first asked whether they had participated in our investigation into food waste before to avoid duplication. Next, the investigators cooperated in collecting and classifying the food scraps. Following Qian et al. [16], the leftovers were divided into 10 items: rice, wheat, pork, beef and mutton, poultry, aquatic products, egg products, bean products, vegetables, and fruits. Using the electronic scales with an accuracy of $0.01 \mathrm{~g}$, the food waste was classified and weighed to acquire waste data in detail. The random sampling method was used in surveying 300-350 students at each university. Finally, with the joint efforts of 29 tutors and 290 trainee investigators over 2 months, 9192 valid samples (Table 1) were obtained with $>30,000$ food trays weighed.

Table 1. Sample characteristics.

\begin{tabular}{cccc}
\hline Characteristics & Categories & Responses & Percentage \\
\hline \multirow{2}{*}{ Gender } & Female & 4418 & $48.06 \%$ \\
& Male & 4774 & $51.94 \%$ \\
Education status & Undergraduate & 7466 & $81.22 \%$ \\
& Postgraduate & 1726 & $18.78 \%$ \\
Ethnicity & Han & 898 & $9.77 \%$ \\
& Minority & 8294 & $90.23 \%$ \\
Family origin & Rural & 3999 & $43.53 \%$ \\
& Town & 2974 & $32.38 \%$ \\
Family economic condition & City & 2213 & $24.09 \%$ \\
(expenditure per month) & 1000-1500 RMB & 4114 & $45.08 \%$ \\
& $>1500$ RMB & 3252 & $35.63 \%$ \\
Mealtime & Lunch & 1760 & $19.29 \%$ \\
Survey days & Dinner & 4973 & $54.65 \%$ \\
& Working days & 4219 & $45.35 \%$ \\
& Nonworking days & 6378 & $69.39 \%$ \\
& South & 2814 & $30.61 \%$ \\
& North & 4471 & $48.64 \%$
\end{tabular}

\subsection{Variables}

In this study, food waste was the explained variable. Three indicators were introduced to show individual food wastage more comprehensively. The first one was a dummy vari- 
able named "Waste food or not". If any edible food was abandoned by a respondent who had leftovers, the value was 1 ; otherwise, the value was 0 . The second proxy was "Weight of food waste" [17]. As the direct weighing method was used, the food waste weight could be obtained directly to measure the absolute scale of food waste. The third indicator was "The ratio of food waste", which could measure the severity of food wastage [16]. Inspired by Wang et al. [39], the ratio was calculated using before- and after-meal food weights.

BMI (body mass index) is one of the leading indicators for measuring body size internationally [20,21] and a crucial criterion for measuring the degree of obesity [23]. We used BMI value as the proxy of body size, following Ou [57]. When BMI falls below a certain standard, it suggests that somebody has a slim stature; when above a certain value, it indicates somebody is overweight. Precisely, BMI was calculated according to the respondent's self-reported weight and height.

Inspired by other studies related to the food waste of university students $[8,10,12,16]$, a series of influencing factors were also introduced as controlled variables in the basic model, including individual-level and family-level characteristics, catering features, information interference, and regional factors.

Specifically, the existing literature indicates that gender, age, and education could affect individuals' food wastage [31,44]. Different ethnicities and religious beliefs imply distinct dining customs, affecting food waste [6,35]. A popular cognition is that people from single-child families are more likely to waste than non-single-child families in China [58]. Additionally, prior studies reported that daily waste habits could not be ignored when explaining food wastage [59]. Thus, the variables mentioned above were used as controlled variables.

For family-level characteristics, three variables, including family origin [12,28], household size [29], and family economic condition were introduced [18,60]. By doing so, the influence of demographic and socioeconomic factors at the family level could be controlled.

For catering features, five variables, including lunch or dinner, weekdays or weekends, type of plate, weight of the purchased meal, and food taste satisfaction, were used to control the influence of food supply in canteens. Some previous studies suggested that food wastage could differ between lunchtime and dinnertime [55,61], between weekends and workdays [13], and between different plate types. Correspondingly, the existing literature argues that food supply exceeding personal demand is a crucial reason for waste [40,62], and the subjective assessment of food taste could also correlate with plate waste $[33,63]$. Thus, the weight of the purchased meal and food taste satisfaction needed to be controlled.

For information interference, several studies indicated that knowledge about food wastage $[19,42]$ and awareness campaigns could help to reduce food wastage significantly $[9,11]$. For example, the "Love food, hate waste" campaign in the UK and the "Stop wasting food" movement in Denmark yielded moderate success [64]. Based on the actual situation in China, two control variables, namely, the frequency of exposure to food-saving information and knowledge about the "Clean your plate" campaign were used in the model. The latter is the most popular food-saving initiative in Chinese colleges.

Finally, China is a vast country with substantial heterogeneity in different regions. Previous studies indicated that the influence of culture and economic differences should not be overlooked [16]. Hence, we introduced three regional dummy variables, including Eastern China and Central China, to control regional economic differences, and a dummy variable named "Southern China" as the proxy of dietary culture divergence between Northern and Southern China [65]. All the variables introduced are listed in Table 2 below. 
Table 2. Variable definitions and descriptive analysis.

\begin{tabular}{|c|c|c|c|}
\hline Variable & Definition & Mean & SD \\
\hline Waste food or not & $1=$ yes, $0=$ no & 0.74 & 0.44 \\
\hline Weight of food waste & The sum weight of different kinds of food items, $(\mathrm{g})$ & 61.03 & 73.71 \\
\hline The ratio of food waste & Weight of food waste $\times 100 /$ weight of the purchased meal, $(\%)$ & 12.13 & 14.55 \\
\hline BMI & $\mathrm{BMI}=\operatorname{weight}(\mathrm{kg}) /$ height $(\mathrm{m})^{2}$ & 20.68 & 2.81 \\
\hline Gender & $1=$ male, $0=$ female & 0.52 & 0.50 \\
\hline Age & Age of the respondent & 21.25 & 2.33 \\
\hline Education & $1=$ postgraduate $0=$ undergraduate & 0.19 & 0.39 \\
\hline Ethnicity & $1=$ Han, $0=$ minority & 0.90 & 0.30 \\
\hline Religious belief & $1=$ yes, $0=$ no & 0.08 & 0.28 \\
\hline Only-child or not & $1=$ yes, $0=$ no & 0.43 & 0.49 \\
\hline Daily waste habits & $1=$ never, $2=$ sometimes, $3=$ often, $4=$ always & 2.11 & 0.61 \\
\hline Family origin & The location of respondent family: $1=$ rural, $2=$ town, $3=$ city & 1.81 & 0.80 \\
\hline Household size & Number of family members & 1.67 & 0.53 \\
\hline Family economic condition & Expenditure per month: $1=\leq 1000 \mathrm{RMB}, 2=1000-1500 \mathrm{RMB}, 3=>1500 \mathrm{RMB}$ & 1.74 & 0.76 \\
\hline Lunch or dinner & $1=$ lunch, $0=$ dinner & 0.55 & 0.50 \\
\hline Weekdays or weekends & $1=$ yes, $0=$ no & 0.70 & 0.46 \\
\hline Type of the plate & $1=$ mix plates, $0=$ subpackage plates & 0.66 & 0.47 \\
\hline Weight of the purchased meal & Standard weight of meal, $(\mathrm{g})$ & 524.54 & 155.38 \\
\hline Food taste satisfaction & $3=$ satisfied, $2=$ neutral, $1=$ unsatisfied & 2.40 & 0.59 \\
\hline $\begin{array}{c}\text { Exposure to food-saving } \\
\text { information }\end{array}$ & $1=$ frequently, $0=$ occasionally & 0.41 & 0.49 \\
\hline Clean your plate & $1=$ quite familiar with the campaign, $0=$ not familiar with the campaign & 0.74 & 0.44 \\
\hline Eastern China & Location of the surveyed university: $1=$ East, $0=$ not East & 0.41 & 0.49 \\
\hline Central China & Location of the surveyed university: $1=$ Central, $0=$ not Central & 0.21 & 0.41 \\
\hline Southern China & Location of the surveyed university: $1=$ South, $0=$ North & 0.49 & 0.50 \\
\hline
\end{tabular}

\subsection{Empirical Models}

To analyze the impact of body size on food wastage, the benchmark models were introduced as follows:

$$
\begin{aligned}
& \text { food }- \text { waste }_{i}=\alpha_{0}+\alpha_{1} B M I_{i}+\sum \alpha_{i} X_{i}+\varepsilon_{i} \\
& \text { waste }- \text { weight }_{i}=\beta_{0}+\beta_{1} B M I_{i}+\sum \beta i X_{i}+\delta_{i} \\
& \text { waste }- \text { ratio }_{i}=\lambda_{0}+\lambda_{1} B M I_{i}+\sum \lambda_{i} X_{i}+\eta_{i}
\end{aligned}
$$

where food-waste $e_{i}$ suggests whether individual $i$ leaves food waste from the meal; wasteweight $_{i}$ denotes the total weight of food wastage after the meal; waste-ratio $i$ presents the food waste rate of the meal; $B M I_{i}$ signifies the individuals' body size; $X_{i}$ implies a series of control variables that correlate with food waste; $\alpha_{0}, \beta_{0}, \lambda_{0}$ are constants; and $\varepsilon_{i}, \delta_{i}$, and $\eta_{i}$ are random errors.

Regarding specific economic models, as food-waste $e_{i}$ denotes a binary dummy variable, Equation (1) was applied to the Probit model. Both waste-weight $t_{i}$ in Equation (2) and wasteratio $_{i}$ in Equation (3) were non-negative variables, and following Mattar et al. [28] and Qian et al. [16], the Tobit model was introduced for analysis.

\section{Empirical Results}

\subsection{Descriptive Analysis}

First, a group-descriptive analysis was performed based on the BMI value. Following prior studies [20,57], when the BMI value is $<18.5$, a Chinese youth is considered slim or underweight; 18.5-24 implies an average weight; and $>24$ signifies overweight. Thus, the overall samples were divided into three groups based on different body sizes (Table 3). Among the three subsamples, the underweight group had the highest probability of wasting food $(80.13 \%)$, as well as the most considerable weight of food wastage $(74.70 \mathrm{~g})$ and the highest waste ratio $(15.19 \%)$. Conversely, the overweight group had the lowest possibility of wasting food $(65.74 \%)$, the lowest amount of plate waste $(49.64 \mathrm{~g})$, and the lowest waste 
ratio $(9.43 \%)$. Thus, slimmer youth tended to waste more food and produce more wastage when dining in university canteens.

Table 3. Descriptive analysis of food waste among different body sizes.

\begin{tabular}{ccccc}
\hline Categories & BMI Value & Food Waste or Not (\%) & Weight of Food Waste (g) & The Ratio of Food Waste (\%) \\
\hline Underweight & BMI $<18.5$ & 80.13 & 74.70 & 15.19 \\
Normal Weight & $18.5 \leq$ BMI $<24$ & 73.17 & 58.82 & 11.67 \\
Overweight & BMI $\geq 24$ & 65.74 & 49.64 & 9.43 \\
Total & 20.68 & 74.01 & 61.03 & 12.13 \\
\hline
\end{tabular}

\subsection{Basic Model}

By using the full samples and according to Equations (1)-(3), the benchmark regressions were performed to verify the impact of body size on food wastage among Chinese youth (Table 4). BMI exerted a significant negative impact on food waste, which is consistent with Wansink and Payne [51]. With the increase in the BMI value, the likelihood of wasting food decreased correspondingly, the weight of wastage was lower, and the waste ratio decreased, implying that body size plays a vital role in affecting the food wastage of Chinese youngsters. When considering the marginal effect, we estimated that when the BMI value increased by 1 unit, the likelihood of wasting declined $0.78 \%$, the average amount of plate waste decreased by $1.52 \mathrm{~g}$, and the ratio of food waste reduced by $0.30 \%$. Thus, the basic model suggested that slimmer youth tended to waste food and generate more food wastage in China.

A series of control variables also significantly affected food wastage by Chinese youth (Table 4), but only eight of them simultaneously affected the three proxies of food waste. In particular, for the individual-level features, females were more likely to waste food than males, which is consistent with Al-Domi et al. [61] and Painter et al. [10]. The postgraduates exhibited a lower probability of food wastage, a lower amount of plate waste, and a smaller food waste ratio than undergraduates, suggesting that food wastage could be reduced with improved education $[17,19]$. Furthermore, daily waste habits were significantly positively correlated with food waste, which confirmed prior studies [66]. Young people with a higher frequency of daily waste were more inclined to generate waste and waste more food, accentuating the need to develop good eating habits $[34,59]$.

For economic characteristics, we found that individuals were more likely to waste food and produce more plate waste when the household economic condition was better, which is highly consistent with the existing studies [16,18].

Regarding catering characteristics, the weight of the purchased meal was positively correlated with plate waste, implying that excessive food supply was not conducive to saving food in university canteens [62,63].

Moreover, food taste satisfaction was significantly negatively correlated with food wastage, suggesting that with the increase in food taste satisfaction, individuals were less likely to waste and wasted less food, which aligns with Lorenz et al. [33]. The dummy variable named "Southern China" at the regional level passed the $1 \%$ significance test, indicating that Northerners wasted more food than Southerners on average, implying the influence of diet culture, which cannot be ignored [16].

\subsection{Heterogeneity Analysis}

It is a popular conception that females and males have significant differences in their perceptions of body size [67]. Accordingly, two subsamples were generated based on gender. BMI was found to significantly affect both males and females (Table 5). However, when considering a marginal effect, to our surprise, on the premise that other variables remained unchanged, BMI showed a more significant impact on males than females. In other words, the food wastage of young males is more likely to be affected by body size. 
Thus, the famous saying that "young females waste more food for their slim figures" might not be accurate for Chinese youth in the surveyed Chinese universities.

Table 4. BMI and food waste: basic model.

\begin{tabular}{|c|c|c|c|}
\hline Variable & Waste Food or Not & Weight of Food Waste & The Ratio of Food Waste \\
\hline BMI & $\begin{array}{c}-0.06^{* * *} \\
(0.01)\end{array}$ & $\begin{array}{c}-1.52 * * * \\
(0.38)\end{array}$ & $\begin{array}{c}-0.30 * * * \\
(0.08)\end{array}$ \\
\hline Gender & $\begin{array}{l}-0.21^{* * *} \\
(0.04)\end{array}$ & $\begin{array}{l}-23.22 * * * \\
(2.15)\end{array}$ & $\begin{array}{c}-4.75^{* * *} \\
(0.43)\end{array}$ \\
\hline Age & $\begin{array}{c}0.01 \\
(0.01)\end{array}$ & $\begin{array}{l}1.30 * * \\
(0.61)\end{array}$ & $\begin{array}{c}0.30^{* *} \\
(0.12)\end{array}$ \\
\hline Education & $\begin{array}{l}-0.14^{* *} \\
(0.06)\end{array}$ & $\begin{array}{l}-8.08^{* *} \\
(3.61)\end{array}$ & $\begin{array}{l}-2.15^{* * *} \\
(0.72)\end{array}$ \\
\hline Ethnicity & $\begin{array}{l}-0.10 * \\
(0.06)\end{array}$ & $\begin{array}{c}0.24 \\
(3.35)\end{array}$ & $\begin{array}{c}0.04 \\
(0.67)\end{array}$ \\
\hline Religious belief & $\begin{array}{c}0.04 \\
(0.06)\end{array}$ & $\begin{array}{l}-2.28 \\
(3.63)\end{array}$ & $\begin{array}{l}-0.004 \\
(0.72)\end{array}$ \\
\hline Only-child or not & $\begin{array}{c}0.01 \\
(0.05)\end{array}$ & $\begin{array}{l}1.85 \\
(2.82)\end{array}$ & $\begin{array}{c}0.43 \\
(0.56)\end{array}$ \\
\hline Daily waste habits & $\begin{array}{c}0.42^{* * *} \\
(0.03)\end{array}$ & $\begin{array}{l}37.66^{* * *} \\
(1.70)\end{array}$ & $\begin{array}{c}7.17^{* * *} \\
(0.34)\end{array}$ \\
\hline Family origin & $\begin{array}{l}-0.01 \\
(0.02)\end{array}$ & $\begin{array}{l}-1.84 \\
(1.42)\end{array}$ & $\begin{array}{l}-0.25 \\
(0.28)\end{array}$ \\
\hline Household size & $\begin{array}{c}0.02 \\
(0.04)\end{array}$ & $\begin{array}{l}2.50 \\
(2.54)\end{array}$ & $\begin{array}{c}0.41 \\
(0.51)\end{array}$ \\
\hline $\begin{array}{l}\text { Family economic } \\
\text { condition }\end{array}$ & $0.09^{* * *}$ & $4.10^{* * *}$ & $0.89^{* * *}$ \\
\hline & $(0.02)$ & $(1.38)$ & $(0.27)$ \\
\hline Lunch or dinner & $\begin{array}{c}0.02 \\
(0.03)\end{array}$ & $\begin{array}{c}2.94 \\
(1.97)\end{array}$ & $\begin{array}{c}0.45 \\
(0.39)\end{array}$ \\
\hline Weekdays or weekends & $\begin{array}{c}0.04 \\
(0.03)\end{array}$ & $\begin{array}{l}4.74^{* *} \\
(2.15)\end{array}$ & $\begin{array}{l}0.88^{* *} \\
(0.43)\end{array}$ \\
\hline Type of the plate & $\begin{array}{l}-0.02 \\
(0.03)\end{array}$ & $\begin{array}{l}3.04 \\
(2.07)\end{array}$ & $\begin{array}{l}0.73^{*} \\
(0.41)\end{array}$ \\
\hline $\begin{array}{l}\text { Weight of the } \\
\text { purchased meal }\end{array}$ & $0.00^{* * *}$ & $0.15^{* * *}$ & $0.01^{* * *}$ \\
\hline Food taste satisfaction & $\begin{array}{c}(0.00) \\
-0.13^{* * *} \\
(0.03)\end{array}$ & $\begin{array}{c}(0.01) \\
-14.32 * * * \\
(1.67)\end{array}$ & $\begin{array}{c}(0.00) \\
-2.65^{* * *} \\
(0.33)\end{array}$ \\
\hline $\begin{array}{l}\text { Frequency of exposure to } \\
\text { food-saving information }\end{array}$ & 0.01 & -0.23 & 0.06 \\
\hline & $(0.03)$ & $(2.08)$ & $(0.41)$ \\
\hline Clean your plate & $\begin{array}{l}-0.07 * \\
(0.04)\end{array}$ & $\begin{array}{l}-1.90 \\
(2.30)\end{array}$ & $\begin{array}{l}-0.27 \\
(0.46)\end{array}$ \\
\hline Eastern China & $\begin{array}{c}0.01 \\
(0.04)\end{array}$ & $\begin{array}{c}9.29^{* * *} \\
(2.33)\end{array}$ & $\begin{array}{c}1.74^{* * *} \\
(0.46)\end{array}$ \\
\hline Central China & $\begin{array}{r}-0.00 \\
(0.04)\end{array}$ & $\begin{array}{l}-4.92 * \\
(2.64)\end{array}$ & $\begin{array}{l}-1.01 * \\
(0.53)\end{array}$ \\
\hline Southern China & $\begin{array}{c}0.14^{* * *} \\
(0.03)\end{array}$ & $\begin{array}{c}20.29^{* * *} \\
(2.02)\end{array}$ & $\begin{array}{l}4.14^{* * *} \\
(0.40)\end{array}$ \\
\hline Constant & $\begin{array}{l}-0.31 \\
(0.28)\end{array}$ & $\begin{array}{c}-82.26^{* * *} \\
(17.89)\end{array}$ & $\begin{array}{l}-5.63 \\
(3.56)\end{array}$ \\
\hline LR chi ${ }^{2}$ & $635.48^{* * *}$ & $1484.25^{* * *}$ & $1115.15^{* * *}$ \\
\hline Pseudo $R^{2}$ & 0.07 & 0.02 & 0.02 \\
\hline Observations & 8097 & 8097 & 8106 \\
\hline
\end{tabular}

Note: ${ }^{* * *}, * *$, and ${ }^{*}$ represent $1 \%, 5 \%$, and $10 \%$ significance levels, respectively; the standard error is included inside parentheses.

Owing to differences in geography, climate, and many other factors, a significant divergence of diet culture exists between Southern China and Northern China. Qinling Mountain and Huaihe River serve as the boundary between North and South China [68]. Southern China comprises rice-cropping regions, while Northern China has wheat-cropping areas [65]. Thus, Southerners enjoy eating rice as the staple food and have developed a "rice" dietary culture. Conversely, Northerners gradually formed a "wheat" dietary pattern [16]. Owing to different dietary cultures between the South and North, whether the body size exerts a different impact on Southerners' and Northerners' food wastage remains 
unclear. Thus, the South and the North groups were generated based on the respondents' home addresses.

Table 5. Comparative analysis of males and females.

\begin{tabular}{|c|c|c|c|c|c|c|}
\hline \multirow{2}{*}{ Variable } & \multicolumn{2}{|c|}{ Food Waste or Not } & \multicolumn{2}{|c|}{ Weight of Food Waste } & \multicolumn{2}{|c|}{ Ratio of Food Waste } \\
\hline & Females & Males & Females & Males & Females & Males \\
\hline BMI & $\begin{array}{c}-0.02 * * \\
(0.01)\end{array}$ & $\begin{array}{c}-0.03^{* * *} \\
(0.01)\end{array}$ & $\begin{array}{c}-0.82 * \\
(0.53)\end{array}$ & $\begin{array}{c}-2.49 * * * \\
(0.53)\end{array}$ & $\begin{array}{c}-0.25^{* *} \\
(0.11)\end{array}$ & $\begin{array}{c}-0.40^{* * *} \\
(0.10)\end{array}$ \\
\hline Controlled variables & Yes & Yes & Yes & Yes & Yes & Yes \\
\hline $\operatorname{LR} \chi^{2}$ & $323.81^{* * *}$ & $286.40 * * *$ & $854.60^{* * *}$ & $584.70^{* * *}$ & $579.57 * * *$ & $367.52^{* * *}$ \\
\hline Pseudo $R^{2}$ & 0.08 & 0.06 & 0.02 & 0.02 & 0.02 & 0.01 \\
\hline Observations & 3942 & 4155 & 3942 & 4155 & 3944 & 4162 \\
\hline
\end{tabular}

Note: ${ }^{* * *},{ }^{* *}$, and ${ }^{*}$ represent $1 \%, 5 \%$, and $10 \%$ significance levels, respectively; the standard error is included inside parentheses. The omitted control variables are consistent with Table 4.

The results revealed that BMI significantly affected both Northerners' and Southerners' food wastage (Table 6), suggesting that the overweight waste more food than the slim, regardless of their home addresses. However, regarding the marginal effect, BMI exerted a more substantial impact on Northerners than Southerners. For Northerners, when the BMI value increased by 1 unit, the likelihood of wasting food dropped by $0.90 \%$, the average amount of wastage decreased by $1.65 \mathrm{~g}$, and the average food waste ratio decreased by $0.32 \%$. For Southerners, however, a one-unit increase in BMI was correlated with a $0.75 \%$ lower probability of wasting, a $1.55 \mathrm{~g}$ lower weight of wastage, and a $0.31 \%$ lower waste ratio.

Table 6. Comparative analysis of Southerners and Northerners.

\begin{tabular}{|c|c|c|c|c|c|c|}
\hline \multirow{2}{*}{ Variable } & \multicolumn{2}{|c|}{ Food Waste or Not } & \multicolumn{2}{|c|}{ Weight of Food Waste } & \multicolumn{2}{|c|}{ Ratio of Food Waste } \\
\hline & South & North & South & North & South & North \\
\hline BMI & $\begin{array}{c}-0.02^{* * *} \\
(0.01)\end{array}$ & $\begin{array}{c}-0.03^{* * *} \\
(0.01)\end{array}$ & $\begin{array}{c}-1.55^{* * *} \\
(0.53)\end{array}$ & $\begin{array}{c}-1.65^{* * *} \\
(0.52)\end{array}$ & $\begin{array}{c}-0.31 \text { *** } \\
(0.11)\end{array}$ & $\begin{array}{c}-0.32^{* * *} \\
(0.10)\end{array}$ \\
\hline Controlled variables & Yes & Yes & Yes & Yes & Yes & Yes \\
\hline $\operatorname{LR} \chi^{2}$ & $366.98^{* * *}$ & $319.48^{* * *}$ & $909.83 * * *$ & $570.48^{* * *}$ & $718.48^{* * *}$ & $375.08^{* * *}$ \\
\hline Pseudo $R^{2}$ & 0.08 & 0.07 & 0.02 & 0.02 & 0.02 & 0.012 \\
\hline Observations & 4200 & 3894 & 4200 & 3894 & 4208 & 3895 \\
\hline
\end{tabular}

Note: ${ }^{* * *}$ represents $1 \%$ significance level; the standard error is included inside parentheses. The omitted control variables are consistent with Table 4.

\subsection{Robustness Check I}

Both the descriptive analysis and the basic regressions revealed that the body size of Chinese youth was closely negatively correlated with food wastage. With the BMI increment, the likelihood, weight, and ratio of food waste decreased correspondingly, suggesting that the slim youngsters wasted more food in China than those who had higher BMI values. To further validate the conclusion, using the normal weight as the reference group [57], two dummies named "underweight" $(1=$ yes; $0=$ no) and "overweight" ( $1=$ yes; $0=$ no) were introduced in the benchmark regression. The criteria for dividing these three groups were based on the descriptive analysis shown in Table 3.

The estimated results revealed that, compared with the normal-weight individuals (Table 7), the underweight were more likely to waste food, and the average weight of wastage, as well as the food waste rate, was significantly higher. However, those who were overweight were less likely to generate plate waste and wasted less food during meals, and they also had a lower waste ratio on average. Thus, the finding that slimmer youth tended to generate waste and waste more food is robust. 
Table 7. BMI and food waste: changing the measurement of body size.

\begin{tabular}{cccc}
\hline Variables & Food Waste or Not & Weight of Food Waste & Ratio of Food Waste \\
\hline Underweight & $0.12^{* * *}$ & $8.51^{* * *}$ & $1.74^{* * *}$ \\
Overweight & $(0.04)$ & $(2.52)$ & $(0.50)$ \\
& $-0.17^{* * *}$ & $-9.51^{* * *}$ & $-1.47^{* *}$ \\
Controlled variables & $(0.05)$ & $(3.32)$ & $(0.66)$ \\
LR $\chi^{2}$ & Yes & Yes & Yes \\
Pseudo $R^{2}$ & $639.82^{* * *}$ & $1483.53^{* * *}$ & $1111.23^{* * *}$ \\
Observations & 0.07 & 0.02 & 0.02 \\
\end{tabular}

Note: ${ }^{* * *},{ }^{* *}$ represent $1 \%$ and $5 \%$ significance level, respectively; the standard error is included inside parentheses. The omitted control variables are consistent with Table 3.

\subsection{Robustness Check II}

When analyzing the possible impact of BMI, individuals who are too thin or too fat are usually removed from the overall sample in some studies. Thus, following the existing literature [69], youth who were too thin $(\mathrm{BMI}<15)$ or obese $(\mathrm{BMI}>28)$ were removed from the full samples to eliminate the extreme cases, and the adjusted new samples were used for robustness testing. The results showed (Table 8) that even if the sample was updated without the extreme values, BMI was still significantly negatively correlated with individuals' food wastage (Table 8), reconfirming that the key finding of the benchmark regression was robust.

Table 8. BMI and food waste: new samples after removing extreme values.

\begin{tabular}{cccc}
\hline Variables & Food Waste or Not & Weight of Food Waste & Ratio of Food Waste \\
\hline BMI & $-0.03^{* * *}$ & $-2.74^{* * * *}$ & $-0.41^{* * *}$ \\
& $(0.01)$ & $(0.59)$ & $(0.08)$ \\
Controlled variables & Yes & Yes & Yes \\
LR $\chi 2$ & $400.97^{* * *}$ & $998.25^{* * *}$ & $703.45^{* * *}$ \\
Pseudo $R^{2}$ & 0.05 & 0.02 & 0.02 \\
Observations & 6294 & 6294 & 6303 \\
\hline
\end{tabular}

Note: ${ }^{* * *}$ represents $1 \%$ significance level; the standard error is included inside parentheses. The omitted control variables are consistent with Table 4.

\subsection{Robustness Check III}

The individual BMI significantly affected the food wastage of Chinese youth. However, previous studies suggested that those who habitually intake more food are more likely to be overweight $[45,70]$. Those with higher BMI values were found to waste less food during meals, implying that food wastage and body size are correlated [25,26]. If this endogenous problem cannot be effectively solved, it is problematic to draw any conclusions. To the best of our knowledge, no research has addressed this issue when analyzing food wastage from the perspective of body size. This study introduced a unique instrumental variable to effectively address the endogenous problem between food wastage and body size.

We value other people's opinions and often adjust our behaviors according to others' feedback to ensure that we align with the social norms. From the biological evolution standpoint, it is reasonable for people to adopt such a strategy if they want to be accepted by others in the group. Several studies have claimed that peer effects play a vital role in people's decision-making, especially for the youth who live in groups. Thus, social interaction and peer effects cannot be ignored when analyzing an individual's body size. Several studies have supported the notion that peer effects have an impact on students obesity or BMI, such as a piece of evidence from China provided by Nie et al. (2015) and a similar study in the United States [69].

For young university students living on campus, if their body size profoundly differs from others, they might be mocked by peers. Assumedly, individuals might adjust their BMI on purpose to ensure a stature similar to others to be accepted. Sheldon [71] discovered 
that university students face pressure to keep their figures similar to their same-sex peers. Hence, inspired by Li et al. [72], the mean BMI value of same-sex students surveyed, except for individual $i$ in each university, was adopted as the instrumental variable for $B M I_{i}$ in this study. Consequently, the university-level average BMI value of each sex satisfied the correlation with $B M I_{i}$ of individual $i$ logically. Meanwhile, the average BMI at the university level and individual's food wastage were exogenous to each other. Thus, the instrument variable fits the restriction.

A two-stage least-squares regression analysis was used based on the instrumental variables. The first-stage regression suggested that individual BMI exhibited a significant positive correlation with the university-level BMI at the $1 \%$ significant level, reconfirming that the peer effect exists among Chinese youth [71,73] and indicating that the instrument variable we selected is not a weak IV. The results revealed that BMI exerted a robust impact on food wastage when the potential endogenous problem was controlled. As the BMI value decreased, both the likelihood of wasting, the amount of wastage, and the food waste rate increased correspondingly (Table 9), further confirming that body size affects the food waste of Chinese youth and that the core finding is credible in this study.

Table 9. BMI and food waste: IV model.

\begin{tabular}{cccc}
\hline Variables & Food Waste or Not & Weight of Food Waste & Ratio of Food Waste \\
\hline BMI & $-0.30^{* * *}$ & $-25.42^{* * *}$ & $-4.20^{* * *}$ \\
& $(0.03)$ & $(5.94)$ & $(1.12)$ \\
Controlled variables & Yes & Yes & Yes \\
alpha & - & $24.04^{* * *}$ & $3.92^{* * *}$ \\
& & $(5.95)$ & $(1.12)$ \\
lns & - & $4.43^{* * *}$ & $2.82^{* * *}$ \\
& & $(0.01)$ & $(0.01)$ \\
lnv & - & $0.95^{* * *}$ & $0.95^{* * *}$ \\
Wald & & $(0.01)$ & $(0.01)$ \\
Observations & $29.35^{* * *}$ & $18.32^{* * *}$ & $12.21^{* * *}$ \\
\hline
\end{tabular}

Note: ${ }^{* * *}$ represents $1 \%$ significance level; the standard error is included inside parentheses. The omitted control variables are consistent with Table 4.

\section{Discussion}

\subsection{Food Waste Generation}

The full sample statistical analysis revealed that food waste is widespread among Chinese youth (Table 3). Nearly $74 \%$ of young university students have plate waste when dining in university canteens. However, the amount of food wastage among Chinese youth is not as severe as in the West. In this study, the amount of food waste per capita per meal was $61.03 \mathrm{~g}$, which is significantly lower than the investigation results of Western youth. For example, Wilkie and Graunke [46] observed an average plate waste of $444 \mathrm{~g} / \mathrm{cap} / \mathrm{meal}$ at the University of Florida. Painter et al. [10] estimated that the average amount of food wastage was about 555 g per student per day at Rhodes University in South Africa. Pinto et al. [11] reported that university students generated about $458 \mathrm{~g}$ of plate waste per capita per meal at the University of Lisbon in Portugal. The food waste rate per student per meal was $12.13 \%$ for Chinese youth, also lower than Western youth [74]. For example, the ratio of food waste for youth at the University of Lisbon in Portugal was about onethird [11], and the average waste rate of youth at Stellenbosch University in South Africa was $16.9 \%$ [55]. In summary, youth in developed countries have a higher level of food wastage compared with Chinese youngsters.

Two reasons might account for a large gap in the food waste scale between Chinese and Western university students. The first is the difference in economic development levels. In general, as individual or family income levels increase, the corresponding food wastage increases $[17,34]$. As the income level of China is still much lower than that of Western developed countries, Chinese university students waste less food. Second, it 
could be because of the significant differences between Chinese and Western countries' diets [16]. The differences in ingredients, cooking methods, and other aspects between Chinese and Western diets are significant; however, this proposition is yet to be validated by future studies.

\subsection{The Possible Mechanism of BMI Affecting Food Wastage}

This study steadily confirms that BMI negatively correlates with food waste. There might be two possible mechanisms behind this phenomenon. First, BMI affects food waste through the physiological pathway. In general, the higher the BMI, the higher the energy requirement for individuals, and the lower the corresponding waste, as also confirmed by previous studies [45]. Second, BMI might display its influence on food waste from the physiological dimension [70]. Affected by the popular concept of "skinny is beautiful", it is a widespread phenomenon for youth to deliberately decrease food intake to maintain their figures or lose weight [67], especially in China. The Chinese news media frequently report that Chinese youth are now more interested in keeping fit with enhanced living standards [40]. Under the popular notion that a slim figure is considered beautiful and charming, many young people desire to attain good physical figures to be more attractive in China. Among the various ways of becoming slim, the most popular is decreasing calorie intake [71]. It has been established that young people waste edible food to avoid excessive calorie intake even though they do not think it is right to do so [67]. Our investigation also found that the food provided in Chinese university canteens is standardized and inflexible to cater to individual needs. Thus, for these young people who intend to stay slim, the food supply is usually in surplus, causing more severe food wastage. Likewise, previous studies suggested that BMI is not a simple medical indicator, but that it also influences an individual's attitude toward food-waste aversion [21]. The higher the BMI value, the weaker the individual's tendency to decrease food waste, denoting that an individual's BMI itself indicates the youth's perception toward food, implying that individuals with a lower $\mathrm{BMI}$ are more motivated to keep slim and that this is the reason that the slim waste more food. Both the theory of planned behavior (TPB) and the theory of reasoned action (TRA) support the notion that attitudes and beliefs play crucial roles in personal behavior [12,75]. Regrettably, this study does not involve the respondents' attitudes, subjective norms, and intentions, and the abovementioned inferences are indirect or just a conjecture. Hence, this study cannot confirm the actual mechanisms through which BMI impacts food wastage, whether it is because of physical needs or young people's perception of body size, which needs to be verified by further studies.

\subsection{Potential Intervention Strategies}

There is a growing interest among policymakers toward decreasing food wastage because of nutritional loss and environmental and economic concerns. Based on the empirical findings of this paper, several implications can be drawn from this study.

First, policymakers should pay close attention to young people's food wastage, although Chinese youth waste less than their Western peers at present. However, the food wastage issue would worsen without intervention when income increases [42,43]. Thus, policy interventions are needed to reduce potential food wastage. Many studies have supported the idea that social norms for saving food [47], broaden young people's knowledge about food waste $[49,50]$ and deepen their awareness of the negative environmental effects caused by food wastage [7,12], which would help decrease the food waste of youth. Thus, intervention from the three abovementioned standpoints needs to be popularized in Chinese university campuses as soon as possible. Furthermore, the legal constraint is also vital in preventing and managing food waste. Fortunately, the Chinese government has realized the danger of food waste and promulgated the Anti-Food Waste Law in April 2021. The intentional waste of food will be punished by law in China. Nevertheless, the implementation of this law and the effect on food wastage of Chinese youth remain to be studied by follow-up studies. 
Second, although body size exerts a significant impact on food wastage, it does not signify that we should encourage people to eat more than enough to decrease waste, because obesity and excessive energy consumption are also other wastage. From a nutrition perspective, eating food that exceeds one's nutritional needs is another type of waste [60]. Besides, it may not be cost-effective at the economic level, because the problem of overnutrition and rising medical costs [70] caused by excessive intake is already severe in China. As this study establishes that BMI is negatively correlated with food wastage, young people need to be guided to develop good health habits and food consumption conception; this will not only help to reduce the economic losses and negative environmental effects caused by food wastage but will also be highly beneficial for the sustainable development of the food system [35]. If they need to decrease energy intake, it is better to purchase the right amount of food and avoid excessive consumption. In contrast, the deliberate wastage of food to stay slim should be discouraged, condemned, and punished. From the management of universities and canteens, it is recommended that they design more standardized menus so that people of different weights can choose different amounts of food, especially providing small portions for females and slimmer individuals. At present, the standardized menu of food in Chinese university canteens is too homogenous and lacks hierarchy [16], which could be one of the key reasons young people waste more food. A potential direction is that universities and restaurants provide reasonable, detailed, healthy, and nutritious dining guidelines based on individuals' BMI, and guide young people to purchase food reasonably [50], to decrease food waste from the source.

Third, education plays an influential role in reducing plate waste. With a higher education level, Chinese youth were found to be less likely to generate waste, to have less food wastage, and to have a lower food waste ratio. Thus, the findings indicate that it is possible to decrease food wastage through education, which has been validated by the existing studies [17].

Fourth, a good eating habit is essential for reducing plate waste. This study illustrates that good eating habits could reduce leftovers; thus, young people should be nurtured to cherish food and develop daily habits that do not waste food.

Fifth, over-consumption is a significant cause of plate waste. The study implies that excessive food supply leads to more waste, and young people should be guided to purchase food reasonably and decrease unnecessary waste caused by extravagance. Owing to the strong demand for abundant food among young college students, university canteens may consider providing them with small meals, which will help decrease food waste [8].

Finally, we found that diet culture is significantly correlated with food wastage by youth. Hence, diet culture is a crucial determinant of wastage, which cannot be overlooked, and we should further investigate how diet culture affects food wastage.

\section{Conclusions}

\subsection{Summary of the Findings}

With the first-hand data collected at 29 colleges in 29 provinces of China, we set university students as the representative of the Chinese youth to determine if body size affects food wastage. The statistical description of the overall samples demonstrated that food wastage is highly prevalent among Chinese youth, confirming the findings of Wu et al. [17] and Zhang et al. [8]. Indeed, $74 \%$ of the surveyed students wasted food in canteens, the average amount of plate waste was $61.03 \mathrm{~g} / \mathrm{cap} / \mathrm{meal}$, and the ratio of food waste was $12.13 \%$. The descriptive analysis suggested that the slim are more likely to waste than normal-weight and overweight individuals. The basic model suggested that the probability of waste, the weight of wastage, and the ratio of food waste decrease with the BMI increment. Using other proxies for body size, the robust regression suggested that slim individuals are more likely to waste than normal-weight and overweight individuals. Moreover, the robust regressions based on the new adjusted samples suggested that the slimmer tend to waste food and waste more food in China. An IV was introduced to overcoming possible endogenous problems between body size and food waste. The results 
further showed that slim youth are more likely to generate wastage and waste more food, corroborating the speculation of previous studies [51]. Besides, heterogeneity analysis showed that the impact of BMI on males is more substantial than on females, and the influence on Northerners is more potent than on Southerners, suggesting that body size affects these groups differently. This study interpreted young people's waste performance from the standpoint of body size, thereby providing a unique perspective to understand the motivation of young people's food wastage and enriching related research. Furthermore, this study enriches the relevant studies about body size and individuals' economic and social behaviors.

\subsection{Limitations and Future Research}

This study is one of the first attempts to explain food wastage from the viewpoint of body size in China. Nevertheless, this study has some limitations. First, this study confirmed a close correlation between BMI and food wastage and that a lower BMI brings more food waste for Chinese youth. However, whether this law applies to young people in other countries merits further investigation. Second, this study could not determine how body size affects food waste. BMI might affect young people's food waste through physiological or psychological pathways, but we could not determine the actual mechanism or which pathway exerts a greater impact on the process of generating wastage. Besides, TPB and TRA need to be applied further [12] to verify whether BMI indicates an individual's attitude toward food at the psychological level, thereby indirectly affecting food waste. Third, although several control variables in multiple dimensions were introduced in the study to make a comprehensive investigation, it is possibile that some critical factors were still missing from the analysis. Social norms [47] and the specific dining environment (i.e., congestion, cleanliness, and distance from student residences) should be examined in future research. Fourth, the object of this study was limited to the food wastage of students in university canteens, and it did not involve other young adults in other dining places. This study is one of the initial attempts to examine food wastage among Chinese youth. Hence, caution is needed when promoting the findings of this study because of its limitations.

Author Contributions: Conceptualization, L.Q.; methodology, F.L.; software, L.Q. and H.L.; validation, H.L.; formal analysis, L.Q. and H.L.; investigation, L.Q. and F.L.; data curation, L.Q. and H.L.; methodology, F.L. and L.W.; writing-original draft, L.Q.; writing-review \& editing, H.L. and L.W.; supervision, F.L and H.L.; funding acquisition, L.W. All authors have read and agreed to the published version of the manuscript.

Funding: This research was funded by the National Natural Science Foundation of China (grant numbers: 52081330093; 71803077).

Institutional Review Board Statement: The study did not require an approval by the Ethics committee but it does follow ethics guidelines of authors' institutions.

Informed Consent Statement: Informed consent was obtained from all subjects involved in the study.

Data Availability Statement: The data are available on reasonable request from the first author.

Conflicts of Interest: The authors declare no conflict of interest.

\section{References}

1. Di Stefano, V.; Durazzo, A.; Lucarini, M. Food waste: Treatments, environmental impacts, current and potential uses. Sustainability 2022, 14, 234. [CrossRef]

2. Xue, L.; Liu, X.; Lu, S.; Cheng, G.; Hu, Y.; Liu, J.; Dou, Z.; Cheng, S.; Liu, G. China's food loss and waste embodies increasing environmental impacts. Nat. Food 2021, 2, 519-528. [CrossRef]

3. United Nations Environment Programme (UNEP). The Food Waste Index Report 2021; United Nations: Nairobi, Kenya, 2021.

4. $\quad$ Bai, J.; Zhang, C.; Wahl, T.; Seale, J., Jr. Dining out, the missing food consumption in China. Appl. Econ. Lett. 2016, 23, 1084-1087. [CrossRef]

5. Secondi, L.; Principato, L.; Laureti, T. Household food waste behavior in EU-27 countries: A multilevel analysis. Food Policy 2015, 56, 25-40. [CrossRef] 
6. Thyberg, K.L.; Tonjes, D.J. Drivers of food waste and their implications for sustainable policy development. Resour. Conserv. Recycl. 2016, 106, 110-123. [CrossRef]

7. Nikolaus, C.J.; Nickols-Richardson, S.M.; Ellison, B. Wasted food: A qualitative study of US young adults' perceptions, beliefs and behaviors. Appetite 2018, 130, 70-78. [CrossRef]

8. Zhang, H.; Li, S.; Wei, D.; He, J.; Chen, J.; Sun, C.; Vuppaladadiyam, A.; Duan, H. Characteristics, environmental impact, and reduction strategies of food waste generated by young adults: Case study on university canteens in Wuhan, China. J. Clean. Prod. 2021, 321, 128877. [CrossRef]

9. Whitehair, K.J.; Shanklin, C.W.; Brannon, L.A. Written messages improve edible food waste behaviors in a university dining facility. J. Acad. Nutr. Diet. 2013, 113, 63-69. [CrossRef]

10. Painter, K.; Thondhlana, G.; Kua, H.W. Food waste generation and potential interventions at Rhodes University, South Africa. Waste Manag. 2016, 56, 491-497. [CrossRef]

11. Pinto, R.S.; Dos Santos Pinto, R.M.; Melo, F.F.S.; Campos, S.S.; Cordovil, C.M.-D.S. A simple awareness campaign to promote food waste reduction in a university canteen. Waste Manag. 2018, 76, 28-38. [CrossRef]

12. Burlea-Schiopoiu, A.; Ogarca, R.F.; Barbu, C.M.; Craciun, L.; Baloi, I.C.; Mihai, L.S. The impact of COVID-19 pandemic on food waste behaviour of young people. J. Clean. Prod. 2021, 294, 126333. [CrossRef] [PubMed]

13. Rajan, J.; Fredeen, A.L.; Booth, A.L.; Watson, M. Measuring food waste and creating diversion opportunities at Canada's Green University TM. J. Hunger Environ. Nutr. 2018, 13, 573-586. [CrossRef]

14. García-Herrero, L.; De Menna, F.; Vittuari, M. Food waste at school. The environmental and cost impact of a canteen meal. Waste Manag. 2019, 100, 249-258. [CrossRef] [PubMed]

15. Lee, Y.; Cho, W.; Oh, Y. Comparison of eating behavior between commensality and solo-eating of university students by BMI Korean J. Community Nutr. 2012, 17, 280-289. [CrossRef]

16. Qian, L.; Li, F.; Liu, H.; Wang, L.; McCarthy, B.; Jin, S. Rice vs. wheat: Does staple food consumption pattern affect food waste in Chinese university canteens? Resour. Conserv. Recycl. 2022, 176, 105902. [CrossRef]

17. Wu, Y.; Tian, X.; Li, X.; Yuan, H.; Liu, G. Characteristics, influencing factors, and environmental effects of plate waste at university canteens in Beijing, China. Resour. Conserv. Recycl. 2019, 149, 151-159. [CrossRef]

18. Partearroyo, T.; Samaniego-Vaesken, M.; Ruiz, E.; Aranceta-Bartrina, J.; Gil, Á.; González-Gross, M.; Ortega, M.; Serra-Majem, L.; Varela-Moreiras, G. Plate waste generated by Spanish households and out-of-home consumption: Results from the ANIBES study. Nutrients 2020, 12, 1641. [CrossRef]

19. Pocol, C.B.; Pinoteau, M.; Amuza, A.; Burlea-Schiopoiu, A.; Glogovețan, A.I. Food waste behavior among Romanian consumers: A cluster analysis. Sustainability 2020, 12, 9708. [CrossRef]

20. Morris, S. Body mass index and occupational attainment. J. Health Econ. 2006, 25, 347-364. [CrossRef]

21. Raghunathan, R.; Chandrasekaran, D. The association between the attitude of food-waste-aversion and BMI: An exploration in India and the United States. J. Consum. Psychol. 2021, 31, 81-90. [CrossRef]

22. Sellaro, R.; Colzato, L.S. High body mass index is associated with impaired cognitive control. Appetite 2017, 113, 301-309. [CrossRef] [PubMed]

23. Jha, R.; Gaiha, R.; Pandey, M.K. Body mass index, participation, duration of work and earnings under the National rural employment guarantee scheme: Evidence from Rajasthan. J. Asian Econ. 2013, 26, 14-30. [CrossRef]

24. Pfeiler, T.M.; Egloff, B. Personality and eating habits revisited: Associations between the big five, food choices, and body mass index in a representative Australian sample. Appetite 2020, 149, 104607. [CrossRef] [PubMed]

25. Banik, R.; Naher, S.; Pervez, S.; Hossain, M.M. Fast food consumption and obesity among urban college going adolescents in Bangladesh: A cross-sectional study. Obes. Med. 2020, 17, 100161. [CrossRef]

26. Shori, A.B.; Albaik, M.; Bokhari, F.M. Fast food consumption and increased body mass index as risk factors for weight gain and obesity in Saudi Arabia. Obes. Med. 2017, 8, 1-5. [CrossRef]

27. Xue, L.; Liu, G.; Parfitt, J.; Liu, X.; Van Herpen, E.; Stenmarck, Å.; O'Connor, C.; Östergren, K.; Cheng, S. Missing food, missing data? A critical review of global food losses and food waste data. Environ. Sci. Technol. 2017, 51, 6618-6633. [CrossRef] [PubMed]

28. Mattar, L.; Abiad, M.G.; Chalak, A.; Diab, M.; Hassan, H. Attitudes and behaviors shaping household food waste generation: Lessons from Lebanon. J. Clean. Prod. 2018, 198, 1219-1223. [CrossRef]

29. Parizeau, K.; von Massow, M.; Martin, R. Household-level dynamics of food waste production and related beliefs, attitudes, and behaviors in Guelph, Ontario. Waste Manag. 2015, 35, 207-217. [CrossRef]

30. Skaf, L.; Franzese, P.P.; Capone, R.; Buonocore, E. Unfolding hidden environmental impacts of food waste: An assessment for fifteen countries of the world. J. Clean. Prod. 2021, 310, 127523. [CrossRef]

31. Wang, L.; Xue, L.; Li, Y.; Liu, X.; Cheng, S.; Liu, G. Horeca food waste and its ecological footprint in Lhasa, Tibet, China. Resour. Conserv. Recycl. 2018, 136, 1-8. [CrossRef]

32. Jeswani, H.K.; Figueroa-Torres, G.; Azapagic, A. The extent of food waste generation in the UK and its environmental impacts. Sustain. Prod. Consum. 2021, 26, 532-547. [CrossRef]

33. Lorenz, B.A.S.; Hartmann, M.; Langen, N. What makes people leave their food? The interaction of personal and situational factors leading to plate leftovers in canteens. Appetite 2017, 116, 45-56. [CrossRef] [PubMed]

34. Stancu, V.; Haugaard, P.; Lähteenmäki, L. Determinants of consumer food waste behavior: Two routes to food waste. Appetite 2016, 96, 7-17. [CrossRef] [PubMed] 
35. Dhar, A.R.; Oita, A.; Matsubae, K. The effect of religious dietary cultures on food nitrogen and phosphorus footprints: A case study of India. Nutrients 2021, 13, 1926. [CrossRef] [PubMed]

36. Ghina, G.; Yehya, N.A. Lebanese meal management practices and cultural constructions of food waste. Appetite 2020, 155, 104803

37. Falasconi, L.; Cicatiello, C.; Franco, S.; Segrè, A.; Setti, M.; Vittuari, M. Such a shame! A study on self-perception of household food waste. Sustainability 2019, 11, 270. [CrossRef]

38. Sheen, F.; Hardman, C.A.; Robinson, E. Food waste concerns, eating behaviour and body weight. Appetite 2020, 151, 104692. [CrossRef]

39. Wang, L.E.; Liu, G.; Liu, X.; Liu, Y.; Gao, J.; Zhou, B.; Gao, S.; Cheng, S. The weight of unfinished plate: A survey based characterization of restaurant food waste in Chinese cities. Waste Manag. 2017, 66, 3-12. [CrossRef]

40. Xu, Z.; Zhang, Z.; Liu, H.; Zhong, F.; Bai, J.; Cheng, S. Food-away-from-home plate waste in China: Preference for variety and quantity. Food Policy 2020, 97, 101918. [CrossRef]

41. Li, Y.; Wang, L.E.; Liu, G.; Cheng, S. Rural household food waste characteristics and driving factors in China. Resour. Conserv. Recycl. 2021, 164, 105209. [CrossRef]

42. Min, S.; Wang, X.; Yu, X. Does dietary knowledge affect household food waste in the developing economy of China? Food Policy 2021, 98, 101896. [CrossRef]

43. Liu, G.; Liu, X.; Cheng, S. Food security: Curb China's rising food wastage. Nature 2013, 498, 170. [CrossRef] [PubMed]

44. Liu, Y.; Cheng, S.; Liu, X.; Cao, X.; Xue, L.; Liu, G. Plate waste in school lunch programs in Beijing, China. Sustainability 2016, 8, 1288. [CrossRef]

45. Ellison, B.; Savchenko, O.; Nikolaus, C.J.; Duff, B.R.L. Every plate counts: Evaluation of a food waste reduction campaign in a university dining hall. Resour. Conserv. Recycl. 2019, 144, 276-284. [CrossRef]

46. Wilkie, A.; Graunke, R.; Cornejo, C. Food waste auditing at three Florida schools. Sustainability 2015, 7, 1370-1387. [CrossRef]

47. Aydin, A.E.; Yildirim, P. Understanding food waste behavior: The role of morals, habits and knowledge. J. Clean. Prod. 2021, 280, 124250. [CrossRef]

48. Principato, L.; Secondi, L.; Pratesi, C.A. Reducing food waste: An investigation on the behaviour of Italian youths. Br. Food J. 2015, 117, 731-748. [CrossRef]

49. Salleh, S.M.; Azman, N.A.N.N.; Selahudin, N.F. Factors contributing to food waste awareness among Malaysian youth. Glob. Bus. Manag. Res. 2020, 12, 139-148.

50. Byker, C.J.; Farris, A.R.; Marcenelle, M.; Davis, G.C.; Serrano, E.L. Food waste in a school nutrition program after implementation of new lunch program guidelines. J. Nutr. Educ. Behav. 2014, 46, 406-411. [CrossRef]

51. Wansink, B.; Payne, C.R. Eating behavior and obesity at Chinese buffets. Obesity 2008, 16, 1957-1960. [CrossRef]

52. Abdullah, N.N.; Mokhtar, M.M.; Bakar, M.H.A.; Al-Kubaisy, W. Fast food consumption and obesity. Asian J. Qual. Life 2017, 2, 11-17. [CrossRef]

53. Hawkins, L.K.; Farrow, C.; Thomas, J.M. Do perceived norms of social media users' eating habits and preferences predict our own food consumption and BMI? Appetite 2020, 149, 104611. [CrossRef] [PubMed]

54. FAO (Food and Agriculture Organisation of the United Nations). Food Wastage Footprint: Impacts on Natural Resources; FAO: Rome, Italy, 2013.

55. Marais, M.L.; Smit, Y.; Koen, N.; Lötze, E. Are the attitudes and practices of foodservice managers, catering personnel and students contributing to excessive food wastage at Stellenbosch University? S. Afr. J. Clin. Nutr. 2017, 30, 60-67. [CrossRef]

56. Derqui, B.; Fernandez, V. The opportunity of tracking food waste in school canteens: Guidelines for self-assessment. Waste Manag. 2017, 69, 431-444. [CrossRef]

57. Ou, S. Are some neighborhoods bad for your waistline? A test of neighborhood exposure effects on BMI. J. Health Econ. 2019, 63, 52-63. [CrossRef]

58. Jiang, J.Q.; Yu, E.T.; Huang, W.Z.; Wang, Z.H. Home food waste in China and the associated determinants. J. Agrotech. Econ. 2018, 9,88-99.

59. Parfitt, J.; Barthel, M.; Macnaughton, S. Food waste within food supply chains: Quantification and potential for change to 2050. Philos. Trans. R. Soc. B Biol. Sci. 2010, 365, 3065-3081. [CrossRef]

60. Yu, Y.; Jaenicke, E.C. Estimating food waste as household production inefficiency. Am. J. Agric. Econ. 2020, 102, 525-547. [CrossRef]

61. Al-Domi, H.; Al-Rawajfeh, H.; Aboyousif, F.; Yaghi, S.; Mashal, R.; Fakhoury, J. Determining and addressing food plate waste. Pak. J. Nutr. 2011, 10, 871-878. [CrossRef]

62. Filimonau, V.; Ermolaev, V.A. A sleeping giant? Food waste in the foodservice sector of Russia. J. Clean. Prod. 2021, 297, 126705. [CrossRef]

63. Huang, Z.; Gao, R.; Bawuerjiang, N.; Zhang, Y.; Huang, X.; Cai, M. Food and nutrients intake in the school lunch program among school children in Shanghai, China. Nutrients 2017, 9, 582. [CrossRef] [PubMed]

64. Halloran, A.; Clement, J.; Kornum, N.; Bucatariu, C.; Magid, J. Addressing food waste reduction in Denmark. Food Policy 2014, 49, 294-301. [CrossRef]

65. Talhelm, T.; Zhang, X.; Oishi, S.; Shimin, C.; Duan, D.; Lan, X.; Kitayama, S. Large-scale psychological differences within China explained by rice versus wheat agriculture. Science 2014, 344, 603-608. [CrossRef] [PubMed] 
66. Rada, E.C.; Bresciani, C.; Girelli, E.; Ragazzi, M.; Schiavon, M.; Torretta, V. Analysis and measures to improve waste management in schools. Sustainability 2016, 8, 840. [CrossRef]

67. Tanenbaum, H.C.; Felicitas, J.Q.; Li, Y.; Tobias, M.; Chou, C.P.; Palmer, P.H.; Xie, B. Overweight perception: Associations with weight control goals, attempts, and practices among Chinese female college students. J. Acad. Nutr. Diet. 2016, 116, 458-466. [CrossRef]

68. Chen, Y.; Ebenstein, A.; Greenstone, M.; Li, H. Evidence on the impact of sustained exposure to air pollution on life expectancy from China's Huai River policy. Proc. Natl. Acad. Sci. USA 2013, 110, 12936-12941. [CrossRef]

69. Pan, L.; Sherry, B.; Park, S.; Blanck, H.M. The association of obesity and school absenteeism attributed to illness or injury among adolescents in the United States, 2009. J. Adolesc. Health 2013, 52, 64-69. [CrossRef]

70. Serafini, M.; Toti, E. Unsustainability of obesity: Metabolic food waste. Front. Nutr. 2016, 3, 40. [CrossRef]

71. Sheldon, P. Pressure to be perfect: Influences on college students' body esteem. South. Commun. J. 2010, 75, 277-298. [CrossRef]

72. Li, L.; Hu, B.; Zheng, Y.Y. Is obesity contagious? China Econ. Q. 2016, 15, 429-452.

73. Nie, P.; Sousa-Poza, A.; He, X. Peer effects on childhood and adolescent obesity in China. China Econ. Rev. 2015, 35, 47-69. [CrossRef]

74. Martin, M.; Danielsson, L. Environmental implications of dynamic policies on food consumption and waste handling in the European Union. Sustainability 2016, 8, 282. [CrossRef]

75. Fiore, M.; Pellegrini, G.; Sala, P.L.; Conte, A.; Liu, B. Attitude toward food waste reduction: The case of Italian consumers. Int. J. Glob. Small. Bus. 2017, 9, 185-201. [CrossRef] 